\title{
Cholesterol biosynthesis pathway as a novel mechanism of resistance to estrogen deprivation in estrogen receptor-positive breast cancer
}

Nikiana Simigdala ${ }^{1}$, Qiong Gao ${ }^{1}$, Sunil Pancholi ${ }^{1}$, Hanne Roberg-Larsen², Marketa Zvelebil ${ }^{1}$, Ricardo Ribas ${ }^{1}$, Elizabeth Folkerd ${ }^{1,3}$, Andrew Thompson ${ }^{4}$, Amandeep Bhamra ${ }^{4}$, Mitch Dowsett ${ }^{1,3}$ and Lesley-Ann Martin ${ }^{1 *}$

\begin{abstract}
Background: Therapies targeting estrogenic stimulation in estrogen receptor-positive (ER+) breast cancer (BC) reduce mortality, but resistance remains a major clinical problem. Molecular studies have shown few high-frequency mutations to be associated with endocrine resistance. In contrast, expression profiling of primary ER+ BC samples has identified several promising signatures/networks for targeting.

Methods: To identify common adaptive mechanisms associated with resistance to aromatase inhibitors (Als), we assessed changes in global gene expression during adaptation to long-term estrogen deprivation (LTED) in a panel of ER+ BC cell lines cultured in 2D on plastic (MCF7, T47D, HCC1428, SUM44 and ZR75.1) or in 3D on collagen (MCF7) to model the stromal compartment. Furthermore, dimethyl labelling followed by LC-MS/MS was used to assess global changes in protein abundance. The role of target genes/proteins on proliferation, ER-mediated transcription and recruitment of ER to target gene promoters was analysed.

Results: The cholesterol biosynthesis pathway was the common upregulated pathway in the ER+ LTED but not the ER- LTED cell lines, suggesting a potential mechanism dependent on continued ER expression. Targeting the individual genes of the cholesterol biosynthesis pathway with siRNAs caused a 30-50 \% drop in proliferation. Further analysis showed increased expression of 25-hydroxycholesterol (HC) in the MCF7 LTED cells. Exogenous 25-HC or 27-HC increased ER-mediated transcription and expression of the endogenous estrogen-regulated gene TFF1 in ER+ LTED cells but not in the ER- LTED cells. Additionally, recruitment of the ER and CREB-binding protein (CBP) to the TFF1 and GREB1 promoters was increased upon treatment with $25-\mathrm{HC}$ and 27-HC. In-silico analysis of two independent studies of primary ER+ BC patients treated with neoadjuvant Als showed that increased expression of MSMO1, EBP, LBR and SQLE enzymes, required for cholesterol synthesis and increased in our in-vitro models, was significantly associated with poor response to endocrine therapy.
\end{abstract}

Conclusion: Taken together, these data provide support for the role of cholesterol biosynthesis enzymes and the cholesterol metabolites, $25-\mathrm{HC}$ and $27-\mathrm{HC}$, in a novel mechanism of resistance to endocrine therapy in ER+ BC that has potential as a therapeutic target.

Keywords: Breast cancer, Estrogen receptor, Cholesterol biosynthesis, Oxysterol, Transcriptomics, Proteomics

\footnotetext{
* Correspondence: lesley-ann.martin@icr.ac.uk

${ }^{1}$ The Breast Cancer Now Toby Robins Research Centre, The Institute of

Cancer Research, London SW3 6JB, UK

Full list of author information is available at the end of the article
} 


\section{Background}

Over $80 \%$ of breast cancers (BCs) express estrogen receptor alpha (ER) at primary diagnosis. ER is a transcription factor that controls proliferation and survival by binding and activating estrogen response elements (ERE) on target genes controlling proliferation and survival. Current clinical strategies include the use of endocrine agents, which inhibit estrogen (E) signalling either by blocking the conversion of androgens to $E$ in the case of aromatase inhibitors (AIs), by directly antagonizing ER function with agents such as tamoxifen, which compete with $E$ for the ER and results in the recruitment of nuclear corepressors, or by use of drugs such as fulvestrant (ICI182780), which targets ER for proteasomal degradation [1-4].

Despite the efficacy of endocrine therapies, many patients relapse with either de-novo or acquired resistance [4-6]. Preclinical and clinical data support cross-talk between ER and growth factor receptor pathways, such as IGF1R and ERBB2/HER2 [7-10], which can lead to ligand-independent activation of the ER or can alter the phosphorylation state of nuclear co-activators, thereby changing the balance of ER transcription factors and potentiating transcription [11]. Despite this knowledge, few clinical trials have shown benefit from the targeting of endocrine resistance using signal transduction or receptor tyrosine kinase inhibitors. One explanation for this is the complexity/heterogeneity of the tumour background and the lack of definitive biomarkers. Data from large studies such as The Cancer Genome Atlas (TCGA) indicate that other than a small number of high-frequency mutations, such as TP53, PIK3CA and GATA3, which have little association with endocrine resistance [12], primary ER+ BC shows a very low frequency of individual mutations, making targeting difficult. In contrast, expression profiling of primary ER+ BC samples has identified several promising signatures/networks for targeting [13].

Previously, using global gene expression data from patients treated with neoadjuvant anastrozole, we showed that certain gene signatures such as IGF-1, MAPK and obesity were associated with poor response to therapy [13]. In order to identify common adaptive pathways associated with acquired resistance to AIs, we derived a panel of cell lines modelling resistance to E-deprivation and analysed these using both high-throughput transcriptomic and proteomic data. The cholesterol biosynthesis pathway was identified as a common adaptive mechanism only in models that retained ER at the point of resistance. Of particular note, the oxysterols 25-hydroxycholesterol (HC) and 27-HC were shown to influence ER transcriptional activity via recruitment to endogenous E-regulated genes. Furthermore, in-silico interrogation of data from two separate patient cohorts treated with neoadjuvant AIs or adjuvant tamoxifen showed that genes identified within our in-vitro models encoding enzymes within the cholesterol biosynthesis pathway were associated with poor outcome. Overall, these data provide further links between obesity and $\mathrm{BC}$ risk.

\section{Materials and methods \\ Cell culture}

All wild-type (wt) cell lines (MCF7, HCC1428, SUM44, T47D, ZR75.1) were cultured in phenol red-free RPMI supplemented with $10 \% \mathrm{FBS}$ and $1 \mathrm{nM}$ estradiol (E2). Longterm oestrogen-deprivation (LTED) cell lines were cultured in phenol red-free RPMI in the absence of exogenous E2 and supplemented with $10 \%$ dextran charcoal-stripped bovine serum (DCC) [14]. Samples were harvested at baseline, 1 week post E-deprivation and at the point of resistance (LTED). To model the tumour microenvironment during acquisition of resistance to LTED, wt-MCF7 cells were grown on collagen $(3 \mathrm{mg} / \mathrm{ml})$ and were referred to as 3D culture.

\section{Gene expression analysis}

RNA was extracted using RNeasy columns (Qiagen, Crawley, UK), according to the manufacturer's protocol. RNA amplification, labelling and hybridization were conducted on HumanHT-12_V4 Expression BeadChips (Illumina, San Diego, CA, USA), according to the manufacturer's instructions. Data were normalized using variance-stabilizing transformation (VST) and robust spline normalization (RSN) in the Lumi package [15] [GEO Accession number, GSE75971]. Each triangular comparison per cell line was normalized separately. Probes that were not detected in any sample (detection $p>0.01$ ) were discarded. Triangular pairwise comparisons were carried out using BRB-ArrayTools [16]. Differentially expressed probes were considered using the following criteria: False Discovery Rate (FDR) $<5 \%$, unadjusted $p<0.001$ and absolute fold-change $\geq 1.5$. Pathway analyses were performed using Ingenuity Pathway Analysis (IPA).

\section{Proteomics}

Peptides from wt-MCF7 and MCF7 LTED cells were isotopically labelled directly using Sep-pak C18 cartridges, as described previously $[17,18]$. The wt cells were labelled with the medium isotope reagent and the MCF7 LTED cells with the light isotope reagent. After labelling, each sample was eluted using $80 \%$ acetonitrile with $2 \%$ formic acid. Subsequently, the two labelled samples were pooled at an approximate 1:1 ratio and dried down under vacuum. The dried sample was reconstituted in OFFGEL (OGE, Agilent 3100 OFFGEL Fractionator Kit) stock solution and run using $12 \mathrm{~cm}$ IPG strip $\mathrm{pH}$ 3-10. Fractions were desalted (SUM SS18V; The Nest Group Inc., Southborough, MA, USA) and run through liquid chromatographytandem mass spectrometry (LC-MS/MS) using LTQ Velos 
Orbitrap MS. For MS analysis, the data acquisition mode was set to acquire one full-scan spectrum $(350-1850 \mathrm{~m} / \mathrm{z})$. After a survey scan, the 20 most intense precursor ions were selected for subsequent fragmentation. For collisioninduced dissociation, normalized collision energy was set to $35 \%, q$ value to 0.25 and activation time to $10 \mathrm{~ms}$. The isolation width was set to 1.5 and the dynamic exclusion to 1. Raw data were processed using MaxQuant 1.5.1.0 following guidelines by the developers [19-21]. Light and medium dimethyl labels $(+28.0313 \mathrm{Da}$ and $+32.0564 \mathrm{Da}$, respectively) were searched at lysine residues and peptide $\mathrm{N}$-termini. Resulting peptide and protein lists were filtered to an estimated FDR of $1 \%$ and $5 \%$, respectively. Search parameters were chosen as follows: carbamidomethylation was set as a fixed modification on all cysteines. Oxidation of methionines and $\mathrm{N}$-acetylation were considered variable modifications. Precursor ion mass tolerance was set to 20 ppm for the first search and fragment ion mass tolerance was set to $0.6 \mathrm{Da}$. The 'Re-quantify' and 'match between runs' options were enabled. The automatic decoy search option was also enabled. Spectra were searched for a match to fully-tryptic peptides with up to two missed cleavage sites. All proteomics data are deposited with the PRIDE database with the accession number PXD004085.

\section{Proliferation assays}

Cells were seeded in $10 \%$ DCC into 96-well tissue culture plates and allowed to acclimatize overnight. To assess response of the LTED lines in the presence of estrogen, monolayers were treated with $10 \%$ DCC with or without the presence of escalating concentrations of E2. The medium was replaced after 3 days and cells were cultured for a total of 6 days. For the siRNA knockdown studies, cells were seeded in $10 \%$ DCC and transfected with sicontrol (non-targeting pool) or siRNA targeting MSMO1, IDI1, SQLE, and EBP (ON-TARGETplus siRNA; GE Dharmacon, Little Chalfont, Buckingshire, UK) using lipofectamine RNAimax (Invitrogen, Grand Island, NY, USA) [22], according to the manufacturer's protocol. After 24 hours, monolayers were then treated with $10 \%$ DCC with or without the presence of $1 \mathrm{nM} \mathrm{E2}$ and cells cultured for a total of 6 days. Each experiment was performed at least twice with eight replicates per treatment. To assess the effect of oxysterols or cholesterol, wt-MCF7 cells were stripped from E2 for 72 hours. They were then seeded into 96-well plates and were allowed to acclimatize for 24 hours. The medium was changed on day 3 . The cells were treated for 6 days. Cell viability was determined using the CellTitre-Glo ${ }^{\circ}$ Luminescent Cell Viability Assay (Promega, Madison, WI, USA), according to the manufacturer's protocol. Values were expressed as fold-change relative to the vehicle-treated control. As a secondary analysis, absolute cell number was also assessed using coulter counts, as described previously [23].

\section{Transcription assays}

The wt cells were stripped of E2 as described previously and seeded into 24-well plates [24]. The following day, the cells were transfected with an ERE-linked luciferase reporter (EREtkLuc) and $\beta$-galactosidase constructs using Fugene $^{\circ} 6$ (Promega, Madison, WI, USA) [24]. The luciferase activity (Promega, Madison, WI, USA) and $\beta$ galactosidase (GalactoStar; Applied Biosystems, Paisley, Scotland, UK) were measured using a luminometer. Each experiment was performed in triplicate and the luciferase values were normalized to the $\beta$-galactosidase.

\section{Western blot}

Protein extracts were generated as described previously [23]. Equal amounts of protein $(25 \mu \mathrm{g})$ were resolved by SDS-PAGE and subjected to immunoblot analysis. Antigen-antibody interactions were detected with ECL reagent (Amersham, Amersham, UK). Proteins were detected using the following antibodies: ER (sc-8002; Santa Cruz Biotechnology, Dallas, Texas, USA) and $\alpha$-tubulin (SigmaAldrich, Poole, Dorset, UK). Secondary antibodies were used at concentration of 1/2000 (Dako, Denmark).

\section{Quantitative RT-PCR}

RNA was extracted 24 hours after treatments using RNeasy columns and quantification was performed using a NanoDrop 1000 spectrometer. cDNA was generated using the SuperScript III First Strand Synthesis System for RT-PCR (Invitrogen). cDNA was subjected to quantitative PCR in triplicate (Applied Biosystems, Paisley, Scotland, UK). Taqman gene expression assays (Applied Biosystems, Paisley, Scotland, UK) were used for TFF1 (Hs00907239_m1) together with FKBP15 (Hs00391480_m1) as the housekeeping gene, to normalize the data. The relative quantity was determined using $\Delta \Delta \mathrm{Ct}$.

\section{Chromatin immunoprecipitation quantitative PCR}

Chromatin immunoprecipitation (ChIP) experiments were performed, as described previously [25]. Cells were synchronized with $\alpha$-amanitin [26] and then treated for 45 minutes with $27-\mathrm{HC}$ or $25-\mathrm{HC}(10 \mu \mathrm{M})$ [27] and fixed. The antibodies used were anti-ER (sc-543 X; Santa Cruz Biotechnology, Dallas, Texas, USA), anti-CBP (sc-369 X; Santa Cruz Biotechnology, Dallas, Texas, USA) and mouse IgG1 (Dako). The resulting DNA was subjected to quantitative PCR analysis using SYBR green (Applied Biosystems, Paisley, Scotland, UK) with the following primers: for TFF1, forward $5^{\prime}$-GGC CAT CTC TCA CTA TGA ATC ACT TCT GCA-3' and reverse 5'-GGC AGG CTC TGT TTG CTT AAA GAG CGT TAG-3'; and for GREB1, forward 5'-GAA GGG CAG AGC TGA TAA CG-3' and reverse 5'-GAC CCA GTT GCC ACA CTT TT-3'. 


\section{Estradiol assay}

E2 was measured in whole cell extracts and in cell culture media from the target cell lines using a radioimmunoassay with minor modifications. The intra-assay and inter-assay coefficient of variation (CV) for E2 at a mean of $32 \mathrm{pmol} / \mathrm{l}$ was $12 \%$ and $20 \%$, respectively [28].

\section{Oxysterol measurements}

Cells were grown under basic conditions up to $70-80 \%$ confluency, harvested and cell numbers counted using a Beckman coulter counter. Cells were then pelleted and resuspended in $300 \mu$ ice-cold ultra-pure ethanol (Rathburn Chemicals Ltd, Walkerburn, Peeblesshire, UK) containing $400 \mathrm{nM}$ cholesterol-25,26,27- ${ }^{13} \mathrm{C}_{3}$. Oxysterols were quantified as described previously [29].

\section{In-silico modelling analysis of $25-\mathrm{HC}$ and $27-\mathrm{HC}$}

Docking of $27-\mathrm{HC}$ and $25-\mathrm{HC}$ was carried out using SwissDock $[30,31]$ to obtain docking orientations. The most favourable orientation in the ER ligand-binding domain (LBD) was selected. Slight manual manipulation was performed to obtain a better correlation between the binding of $\mathrm{E} 2$ and $27-\mathrm{HC}$ or $25-\mathrm{HC}$ within the binding pocket, as well as similar hydrogen bonding.

\section{Clinical analysis}

The clinical relevance of the observations made in this study was tested in two clinical cohorts of patients with primary $\mathrm{ER}+\mathrm{BC}$ treated with neoadjuvant anastrozole $[32,33]$ or letrozole [34]. In the first study, response was based on the Ki67 value less than $10 \%$ after 2 weeks of therapy $[12,35]$. In the second study, a reduction in tumour volume of $\geq 50 \%$ was defined as response [34]. $p$ values were calculated using the Mann-Whitney $U$ test with $p<0.05$ regarded as significant. Spearman's rank correlation was used for the associations between ontreatment gene expression and 2-week Ki67 protein expression. All p values reported are two tailed.

To test the impact in patients treated with tamoxifen, we generated an integrated $\mathrm{BC}$ cohort of 747 unique baseline sample profiles based on four publicly available gene expression datasets (GSE6532, GSE9195, GSE17705 and GSE26971). All samples were from patients with ER+, HER2-, tamoxifen-treated (followed by AIs in some cases) disease, without chemotherapy and with follow-up information of relapse-free survival (RFS) up to 10 years. The raw data were normalized on an Affymetrix platform basis: HGU133A; or HG-U133plus2 using just the MAS function from the simpleaffy $\mathrm{R}$ package (http://www.bioconductor. org/) to a mean target intensity of 600 , without background correction. The two normalized datasets were then merged and the batch effects across the cohorts were corrected using the ComBat from Surrogate Variable Analysis (sva) R package. Significant impact on RFS was assumed with log- rank $p<0.05$. The samples were stratified into two groups by the median of gene expression.

The same parameters were used to evaluate the cholesterol biosynthesis genes on $496 \mathrm{ER}$ - patients treated with chemotherapy, excluding endocrine therapy [36]. A significant impact on RFS was assumed to be present with $\log$-rank $p<0.05$.

\section{Results}

Transcriptomic and proteomic analysis showed upregulation of cholesterol biosynthesis pathway was restricted to ER+ LTED cells

To identify novel mechanisms of resistance to Edeprivation, we first generated five LTED cell lines. wtMCF7, wt-ZR75.1, wt-T47D, wt-HCC1428 and wt-SUM44 cells were cultured in the absence of E2 until their growth rate was shown to be independent of the exogenous E2 (Fig. 1a). At the point of resistance, ZR75.1 LTED and T47D LTED cells lost expression of ER whilst MCF7 LTED, SUM44 LTED and HCC1428 LTED cells retained or even upregulated ER expression (Fig. 1b). Pellets derived from the wt cells (representing primary diagnosis) 1-week post E2-deprivation (representing clinical response to $\mathrm{AI}$ therapy) and LTED (modelling relapse on an AI) were harvested and global gene expression was interrogated for each cell line using a triangular pairwise comparison (FDR $<5 \%$, univariate $p<0.001$ and absolute fold-change $\geq 1.5$ ) (Fig. 1c). Varying numbers of genes were altered at each time point and differed among cell types, indicating heterogeneity in response to E2-deprivation (Additional file 1: Table S1). As noted previously, comparison between gene changes in wt cells and those deprived of E2 for 1 week were dominated by proliferation, as was the comparison between 1-week deprivation and LTED [24]. We therefore restricted our pathway analysis to comparison of the wt cell lines with their corresponding LTED derivative, in order to remove the confounding effect of proliferation. To identify common adaptive pathways, the IPA software was employed. Strikingly, the cholesterol biosynthesis pathway (Additional file 2: Figure S1) [37-40] was upregulated exclusively in all LTED derivatives that retained expression of ER both in 2D and 3D culture (Table 1). Further interrogation of the gene expression data showed that genes encoding enzymes within the cholesterol biosynthesis pathway were increased significantly (Additional file 3: Table S2).

As protein and mRNA expression is often disconnected, we carried out quantitative proteomic analysis of wt-MCF7 and MCF7 LTED cells using chemical labelling $[17,18]$. Approximately 5000 proteins were identified and 1009 were upregulated in the MCF7 LTED cells compared with wt-MCF7 (Fig. 1d) using the following filter: FDR $\leq 5 \%$ and absolute fold-change $\geq 1.5$. Within the proteins identified were ESR1, in keeping with our western blot analysis, together with GREB1, TFF1 and GATA3 (Additional file 4: 
a
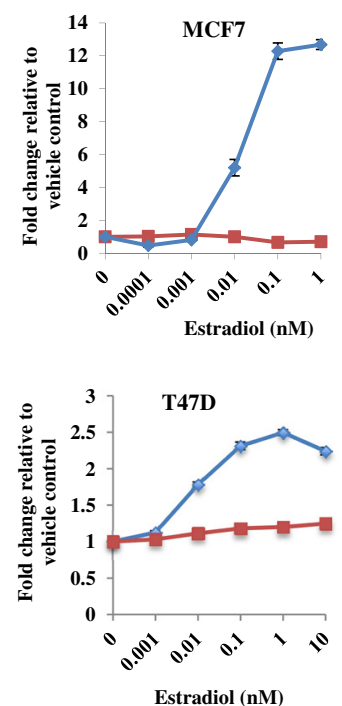
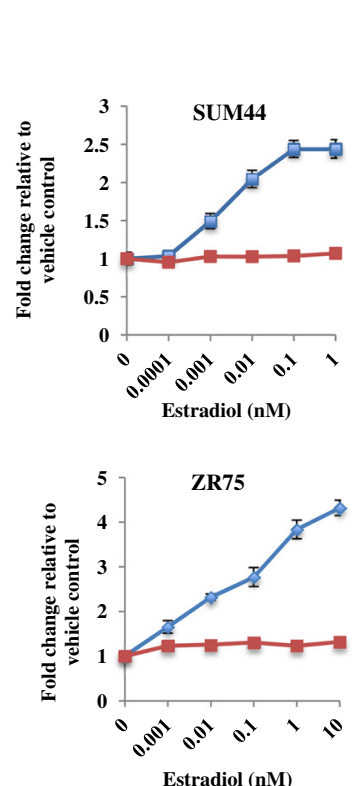

wt

LTED

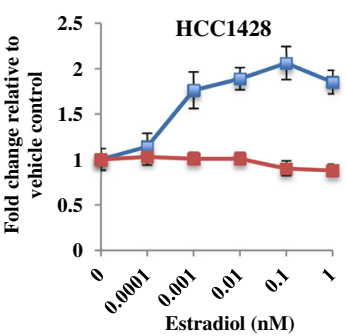

b

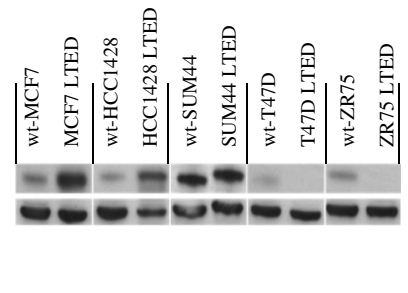

c

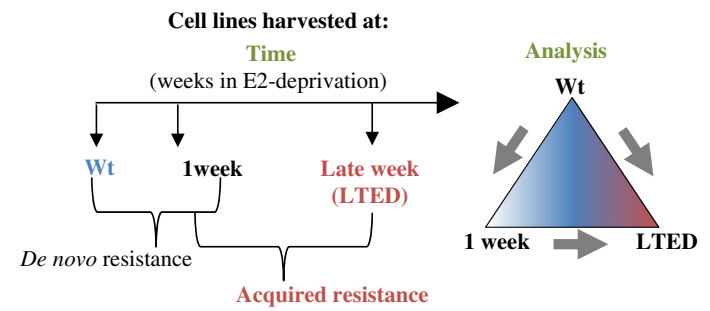

d

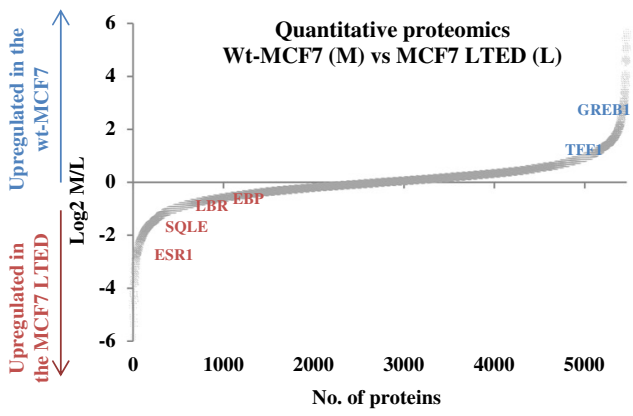

Fig. 1 LTED cell lines are refractory to the addition of exogenous E2. a wt and LTED cell lines were treated for 6 days with escalating concentration of E2. Proliferation was expressed as the fold-change relative to vehicle-treated control. Data shown are representative of three independent biological experiments with eight replicates per treatment. Bars: \pm SEM. $\mathbf{b}$ Western blot analysis assessing ER expression in wt cell lines versus their LTED derivatives. T47D and ZR75.1 lost ER expression, whilst MCF7, SUM44 and HCC1428 retained ER expression. c Schematic representation of the triangular pairwise comparison of this study and a diagram depicting the temporal harvesting of samples during acquisition of resistance. $\mathbf{d}$ Protein profile graph depicting differentially abundant proteins between wt-MCF7 and the MCF7 LTED using dimethyl labelling. E2 estradiol, LTED, long-term estrogen deprivation, wt wild type

Table S3). Pathway analysis confirmed the upregulation of the cholesterol biosynthesis pathway in the MCF7 LTED cells (Additional file 5: Table S4). In particular, enzymes such as sterol 8-isomerase (EBP) (fold-change wt/LTED $=-1.54$ ), Lamin-B receptor (LBR) (fold-change wt/LTED $=-1.86$ ) and squalene epoxidase (SQLE) (fold-change wt/ LTED $=-3.2$ ) were evident (Fig. 1d).

\section{Cholesteryl esters are not associated with the LTED phenotype}

Cholesterol plays a major role in both metabolism and cellular architecture. Recent studies have provided a role for cholesteryl esters fuelling the mechanism of invasion and migration and have been associated with more aggressive tumour phenotypes. In particular, recent evidence has 
Table 1 Cholesterol biosynthesis pathways were exclusively upregulated in LTED cell lines retaining ER+

\begin{tabular}{|c|c|c|c|c|c|}
\hline \multirow[t]{2}{*}{ Pathway } & \multicolumn{3}{|l|}{ ER+ } & \multicolumn{2}{|l|}{ ER- } \\
\hline & $\begin{array}{l}\text { MCF7 } \\
\text { LTED }\end{array}$ & $\begin{array}{l}\text { HCC1428 } \\
\text { LTED }\end{array}$ & $\begin{array}{l}\text { SUM44 } \\
\text { LTED }\end{array}$ & T47D LTED & ZR75.1 LTED \\
\hline $\begin{array}{l}\text { Xenobiotic } \text { Metabolism } \\
\text { signaling }\end{array}$ & 1.57 & 1.53 & 1.57 & 2.19 & 2.63 \\
\hline $\begin{array}{l}\text { Putrescine Degradation } \\
\text { III }\end{array}$ & 2.17 & 2.02 & 0.00 & 1.71 & 2.45 \\
\hline $\begin{array}{l}\text { Aryl Hydrocarbon } \\
\text { Receptor Signaling }\end{array}$ & 0.00 & 1.48 & 2.92 & 2.46 & 1.60 \\
\hline Histamine Degradation & 1.46 & 1.35 & 3.81 & 0.00 & 1.93 \\
\hline $\begin{array}{l}\text { Trytophan Degradation } \\
\mathrm{X}\end{array}$ & 2.17 & 2.95 & 0.00 & 1.64 & 1.58 \\
\hline $\begin{array}{l}\text { Noradrenaline and } \\
\text { Adrenaline Degradation }\end{array}$ & 1.35 & 1.88 & 0.00 & 1.50 & 1.38 \\
\hline RAR Activation & 1.53 & 1.72 & 0.00 & 0.00 & 3.06 \\
\hline $\begin{array}{l}\text { NRF2-mediated } \\
\text { Oxidative } \quad \text { Stress } \\
\text { Response }\end{array}$ & 0.00 & 2.06 & 0.00 & 3.75 & 3.84 \\
\hline 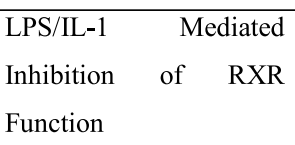 & 1.45 & 0.00 & 0.00 & 3.64 & 3.37 \\
\hline $\begin{array}{l}\text { Cholesterol } \\
\text { Biosynthesis I }\end{array}$ & 1.40 & 1.35 & 2.29 & 0.00 & 0.00 \\
\hline $\begin{array}{l}\text { Cholesterol } \\
\text { Biosynthesis II (via 24- } \\
\text { 25-dihydroxylanosterol }\end{array}$ & 1.40 & 1.35 & 2.29 & 0.00 & 0.00 \\
\hline $\begin{array}{l}\text { Cholesterol } \\
\text { Biosynthesis III (via } \\
\text { Desmosterol }\end{array}$ & 1.40 & 1.35 & 2.29 & 0.00 & 0.00 \\
\hline Ethanol Degradation II & 1.42 & 1.96 & 0.00 & 0.00 & 1.47 \\
\hline Estrogen biosynthesis & 0.00 & 1.79 & 0.00 & 1.42 & 0.00 \\
\hline $\begin{array}{l}\text { Glutathione-mediated } \\
\text { Detoxification }\end{array}$ & 0.00 & 1.43 & 0.00 & 1.82 & 0.00 \\
\hline Dopamine Degradation & 1.84 & 0.00 & 0.00 & 1.31 & 2.85 \\
\hline $\begin{array}{l}\text { N-acetylglucosamine } \\
\text { Degradation II }\end{array}$ & 0.00 & 0.00 & 1.48 & 2.16 & 0.00 \\
\hline
\end{tabular}

Numbers represent $-\log _{10} p$ values. Green data depict ER+ cell lines. Blue data depict ER- cell lines $E R$ estrogen receptor alpha, LTED long-term estrogen deprivation

provided a link between accumulation of cholesteryl esters and loss of PTEN or hyperactivation of the PI3K/AKT/ mTOR axis [41, 42]. Upregulation of the PI3K pathway has been associated with resistance to E2-deprivation [43], so we hypothesized that accumulation of cholesteryl esters may be associated with the LTED phenotype. However, assessment of the gene and protein expression of acetyl-CoA acetyltransferase (ACAT1), 3-hydroxy-3-methylglutaryl-CoA reductase $(H M G C R)$, sterol regulatory element-binding protein $(S R E B P 1)$ and low-density lipoprotein receptor (LDLR) 
$[41,44]$ - central mediators of this pathway - showed that they were either undetected or downregulated (Additional file 6: Tables S5 and Additional file 7: Tables S6).

\section{5-HC and 27-HC enhance ER-mediated transcription in the ER+ LTED models}

We hypothesized that the upregulation of the cholesterol biosynthesis pathway may be related to E2 signalling, since cholesterol is the master precursor of the sterol synthesis cascade. To address this, we measured the intracellular as well as the secreted E2 levels in the LTED cell lines; however, in both cases E2 levels were less than 3pmol. Furthermore, exogenous cholesterol showed no impact on ER-mediated transcription in our LTED models (data not shown).

Recent findings have suggested that cholesterol metabolites, such as $27-\mathrm{HC}$, can act as endogenous ligands for ER [45-47]. In order to investigate this further, we assessed the effect of 25-HC and 27-HC on ER-mediated transcription. wt-MCF7 and MCF7 LTED cells were transfected with an EREtkLuc linked reporter construct and treated with E2, 25- HC and 27-HC alone or in combination with fulvestrant (ICI182780). Both oxysterols increased ER-mediated transcription 2-fold $(p<0.002)$ in the MCF7 LTED but had no effect in wt-MCF7. Furthermore, addition of the pure anti-estrogen fulvestrant, which leads to degradation of ER, suppressed oxysteroldriven ER transactivation (Fig. 2a). These data were confirmed in a separate cell line model, HCC1428 LTED (Fig. 2b), but were not evident in ZR75.1 LTED, which had lost expression of ER (Fig. 2c). Taken together, these data suggest that oxysterols can bind and activate ER.

\section{5-HC and 27-HC show selective estrogen receptor modulator activity and can rescue the anti-proliferative effects of fulvestrant}

To assess the effect of $25-\mathrm{HC}$ and $27-\mathrm{HC}$ on the proliferation of both wt-MCF7 and MCF7 LTED, cells were treated with escalating $\left(\log _{10} \mathrm{M}\right)$ concentrations of E2 or the oxysterols. As expected, E2 caused a concentration-dependent increase in proliferation of wt-MCF7 cells but neither 25HC nor 27-HC showed any significant impact on proliferation when cell viability was measured as the output criterion. In contrast, assessment of absolute cell number showed a small but significant increase (1.4-fold; $p=$ 0.0001 ) in response to $27-\mathrm{HC}$ (Fig. 3b). Of note, addition of $27-\mathrm{HC}$ and $25-\mathrm{HC}$ to E2 showed an antagonistic effect, suggesting that the oxysterols had weak selective estrogen receptor modulator (SERM) activity (Fig. 3a), an observation supported by previous findings $[27,45,48]$. Despite the effect on transcription, proliferation of MCF7 LTED cells was unchanged by addition of E2, 25$\mathrm{HC}$ or $27-\mathrm{HC}$ when measured using cell viability (Fig. 3c). In contrast, assessment of changes in absolute cell number revealed a small but significant increase in response to 25 -
$\mathrm{HC}$ and $27-\mathrm{HC}$ (1.3-fold, $p=0.01$ and $p=0.003$, respectively) (Fig. 3d). To investigate this further, we assessed the ability of both $25-\mathrm{HC}$ and $27-\mathrm{HC}$ to rescue the antiproliferative effect of fulvestrant in the MCF7 LTED (Fig. 3e). As shown previously [23], fulvestrant caused a concentration-dependent decrease in proliferation with an $\mathrm{IC}_{50}$ of $0.1 \mathrm{nM}$. The addition of either of the oxysterols shifted the fulvestrant dose-response curve to the left approximately 10-fold (approximately $\mathrm{IC}_{50}=1 \mathrm{nM}$ ), suggesting that the oxysterols effectively rescued proliferation (Fig. 3e).

One explanation for the observed results was that the ER+ LTED cells synthesized increased levels of 25-HC and $27-\mathrm{HC}$, leading to increased ER activity in response to loss of the E2 proliferative signal. To address this, we measured the intracellular levels of the oxysterols using LC-MS/MS. There was a significant increase in the levels of 25-HC in the MCF7 LTED compared with their corresponding parental cell line (Fig. 3f). Furthermore, using the crystal structure of the Activation Function 2 (AF2) [49] domain of ER, which incorporates the LBD, both $25-\mathrm{HC}$ and $27-\mathrm{HC}$ were successfully docked and were superimposed on E2, supporting this hypothesis (Fig. 3g).

\section{Treatment with $25-\mathrm{HC}$ or $27-\mathrm{HC}$ increases TFF1 mRNA expression, as a result of enhanced ER recruitment} To assess this hypothesis further, we measured the effect of exogenous $25-\mathrm{HC}$ and $27-\mathrm{HC}$ on the expression of TFF1, an endogenous E-regulated gene. TFF1 was increased in MCF7 LTED cells in response to both oxysterols, whilst having no effect on TFF1 expression in wt-MCF7 (Fig. 4a). ChIP of ER and its co-activator CBP in response to both 25-HC and 27-HC showed enhanced recruitment to both the TFF1 and GREB1 EREs in the MCF7 LTED cells (Fig. 4b, c).

\section{Enzymes controlling $25-\mathrm{HC}$ and $27-\mathrm{HC}$ synthesis are associated with poor clinical response in ER+ BC patients}

To assess the clinical relevance of each of the cholesterol biosynthesis enzymes identified within our transcriptomic and proteomic analysis, we used publicly available datasets for ER+ BC patients treated with neoadjuvant anastrozole [33] or letrozole [34]. Clinical response data were available for 72 patients treated with anastrozole, of which 55 were classed as responders based on a 2-week residual Ki67 score $<10 \%[12,35]$ and 17 were classified as nonresponders. In this setting, on-treatment gene expression of $E B P(p=0.0051)$ and $L B R(p=0.0016)$ were significantly associated with poor response to anastrozole, while the other two candidate genes showed no significant difference (Fig. 5a). We also found that increased on-treatment gene expression of MSMO1 ( $p=0.0019), \operatorname{LBR}(p=0.0270)$ and EBP $(p=0.0027)$ correlated with higher Ki67 expression after 2 weeks of therapy, when expressed as a 
$\mathbf{a}$

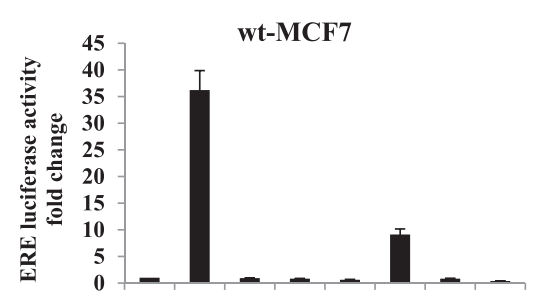

DCC

E2 $(0.001 \mu \mathrm{M})$

$25-\mathrm{HC}(1 \mu \mathrm{M})$

27-HC $(1 \mu \mathrm{M})$

ICI $(0.01 \mu \mathrm{M})$

b

wt-HCC1428

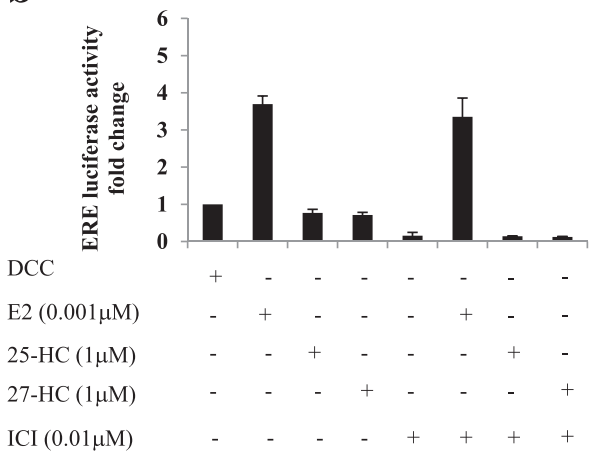

c

ZR75.1 LTED

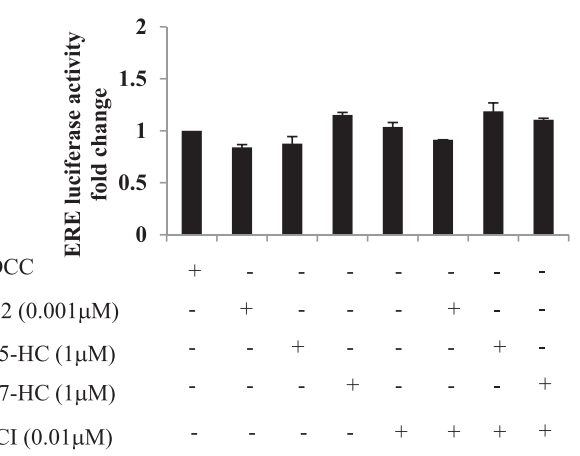

MCF7 LTED

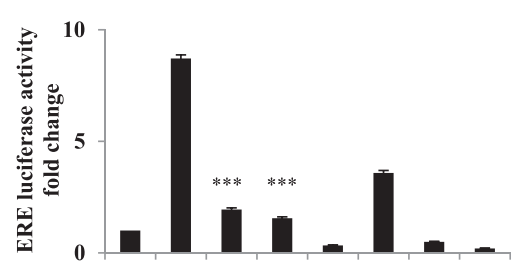

HCC1428 LTED

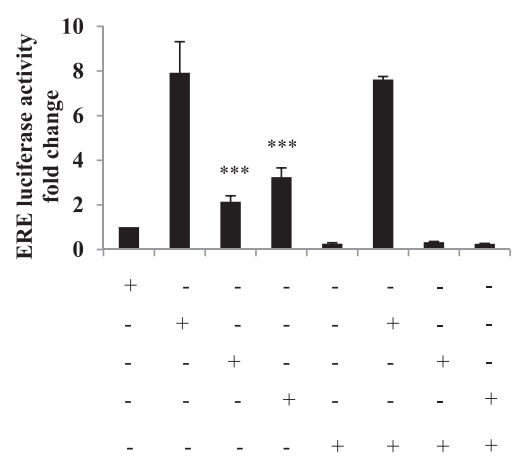

Fig. 2 25-HC and 27-HC increase ER transactivation in LTED cell lines retaining ER. Cell lines were transfected with an ERE-luciferase (EREIl-tk-luc) reporter gene and treated with $\mathrm{E2}, 25-\mathrm{HC}$ and $27-\mathrm{HC}$ alone or in combination with the selective E downregulator fulvestrant (ICI 182780 (ICI)). a wt-MCF7 and MCF7 LTED. b wt-HCC1428 and HCC1428 LTED. c ZR75.1 LTED. Data are representative of three replicates for each treatment. Bars: \pm SEM. DCC Dextran-coated charcoal, ERE estrogen response elements, HC hydroxycholesterol, LTED, long-term estrogen deprivation, wt wild type

continuous variable (Fig. 5b). In the second cohort, data were available for 52 tumours, of which 37 were classified as responders on the basis of tumour shrinkage $\geq 50 \%$. Increased on-treatment expression of methylsterol monooxygenase $1(M S M O 1)(p=0.0404)$ and SQLE $(p=0.0381)$ was strongly associated with poor response to letrozole (Fig. $5 \mathrm{c}$ ). We next assessed whether expression of these genes was also related to long-term outcome on adjuvant tamoxifen. After 10 years of follow-up of $747 \mathrm{ER}+$ patients treated with tamoxifen, only $\operatorname{SQLE}\left(p=5 \times 10^{-6}\right)$ was strongly associated with poor RFS (Fig. 5d). Finally, we assessed the expression of the genes in a cohort of ER- patients treated with chemotherapy and found no significant relationship between expression of the four genes and RFS (Additional file 8: Figure S2A).

siRNA of individual cholesterol-biosynthesis enzymes has an effect on proliferation

To determine the effect of the enzymes associated with poor RFS (MSMO1, LBR, SQLE and EBP) on cell proliferation, 


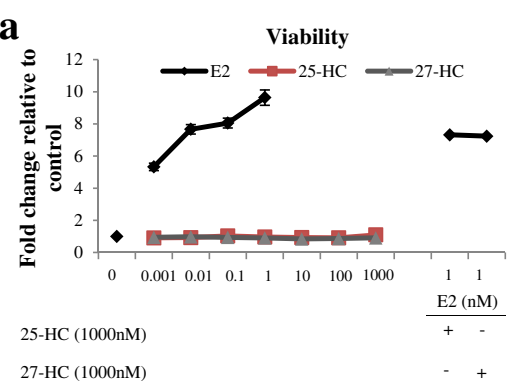

b

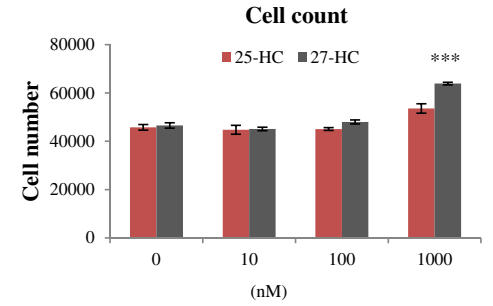

c

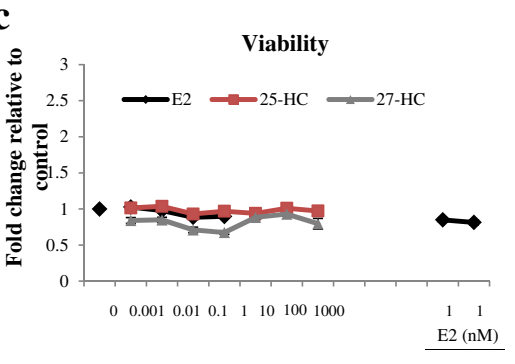

d
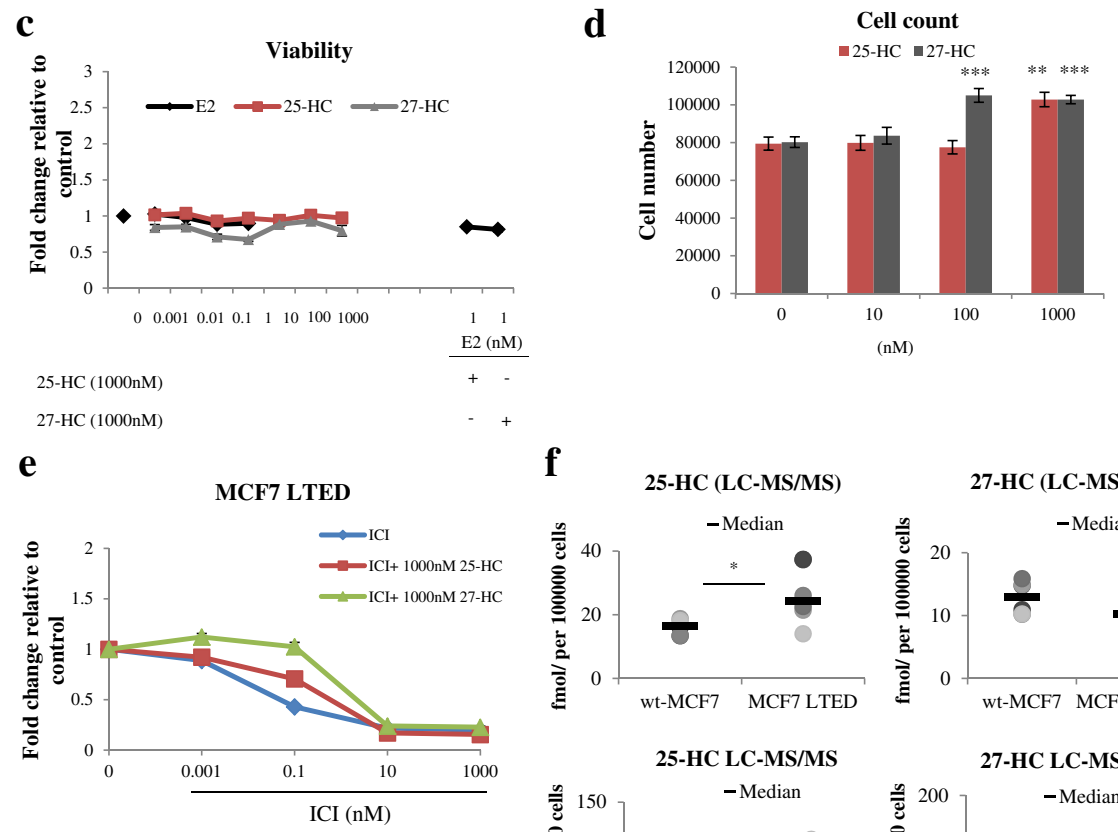

f

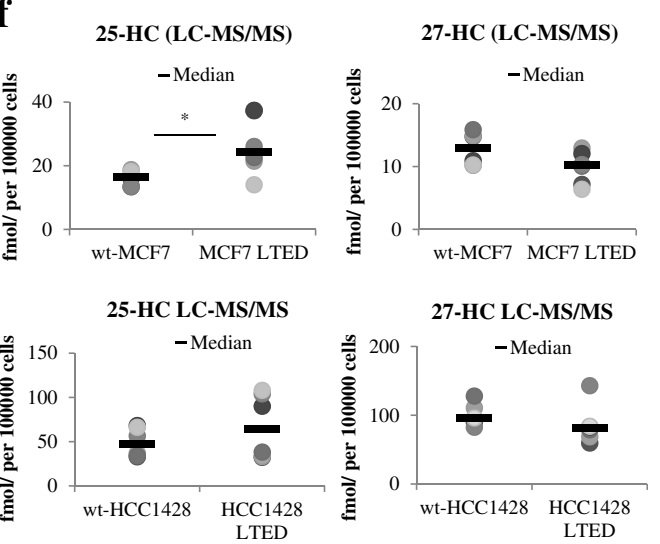

g
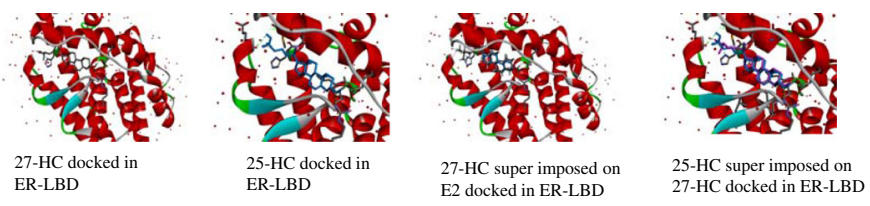

Fig. $325-\mathrm{HC}$ and 27-HC show SERM activity and can rescue the anti-proliferative effect of fulvestrant. wt-MCF7 and MCF7 LTED cells were treated with increasing $\left(\mathrm{Log}_{10} \mathrm{M}\right)$ concentrations of $\mathrm{E} 2,25-\mathrm{HC}$ or $27-\mathrm{HC}$ alone or in combination for 6 days. Proliferation was measured using TitreGlo to assess changes in cell viability and expressed as fold-change versus vehicle-treated control $\mathbf{a}, \mathbf{c}$ or by assessment of changes in absolute cell number $\mathbf{b}, \mathbf{d}$. Data shown are representative of eight replicates per treatment for viability and three replicates per treatment for absolute cell number. Bars: \pm SEM. e MCF7 LTED cells were treated with increasing concentrations of fulvestrant (ICI) alone or in combination with 25-HC or 27-HC (1000 nM). Cell viability was measured using TitreGlo and expressed as fold-change relative to vehicle-treated control. Data shown are representative of eight replicates per treatment. Bars: \pm SEM. $\mathbf{f}$ Levels of 25-HC and 27-HC in whole cell extracts from wt-MCF7, MCF7 LTED, wt-HCC1428 and HCC1428 LTED were measured using LC-MS/MS. Data shown represent the median concentration (fmol/100,000 cells) from two experiments with three biological replicates per cell line. $\mathbf{g}$ In-silico analysis showing docking of both $27-\mathrm{HC}$ and $25-\mathrm{HC}$ to the LBD of ER based on the crystal structure. E2 estradiol, ER estrogen receptor alpha, HC hydroxycholesterol, LBD ligand-binding domain, LC-MS/MS liquid chromatography-tandem mass spectrometry, LTED, long-term estrogen deprivation, wt wild type

we used siRNA knockdown. As expected, inhibition of the four enzymes had no significant effect on ZR75.1 LTED. In contrast, MCF7 LTED showed a $30 \%$ drop in response to siMSMO1 and siSQLE and an approximately $50 \%$ drop in response to siLBR and siEBP. Wt-MCF7 showed no significant decrease in response to siMSMO1, LBR or siSQLE but did show an approximately $30 \%$ reduction in proliferation in response to $\mathrm{si} E B P$. Of note, the anti-proliferative effect of 
a

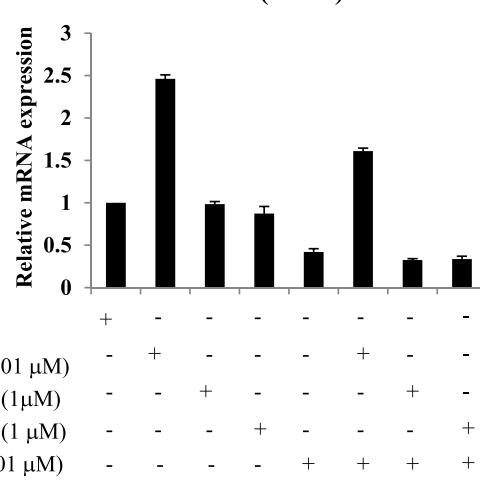

MCF7 LTED (TFF1)

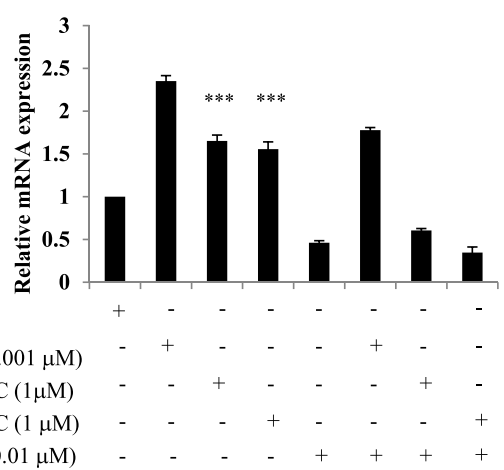

b

MCF7 LTED, 25-HC, TFF1

- DCC $=10 \mu \mathrm{M} 25 \mathrm{HC} \quad 0.1 \mu \mathrm{M} \mathrm{ICI}+10 \mu \mathrm{M} 25 \mathrm{HC}$

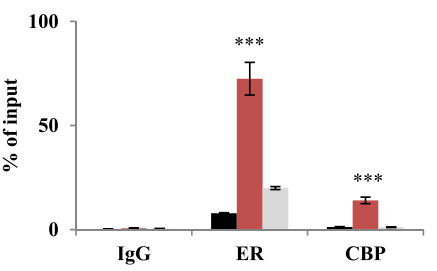

c

MCF7 LTED, 27-HC, TFF1

- DCC $=10 \mu \mathrm{M} 27 \mathrm{HC}=0.1 \mu \mathrm{M} \mathrm{ICI}+10 \mu \mathrm{M} 27 \mathrm{HC}$

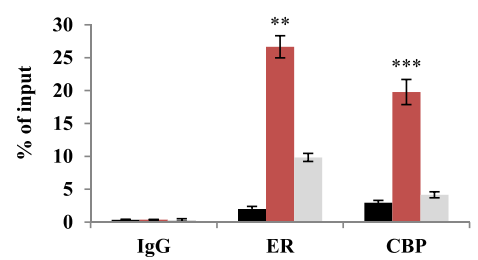

MCF7 LTED, 25-HC, GREB1

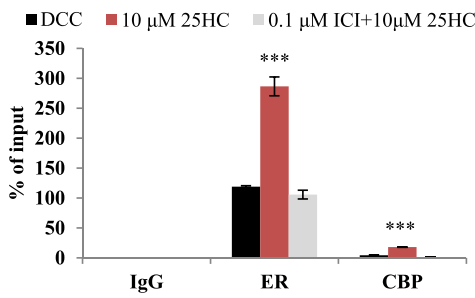

MCF7 LTED, 27-HC GREB1

- DCC $\because 10 \mu \mathrm{M} 27-\mathrm{HC} \quad 0.1 \mu \mathrm{M} \mathrm{ICI}+10 \mu \mathrm{M} 27-\mathrm{HC}$

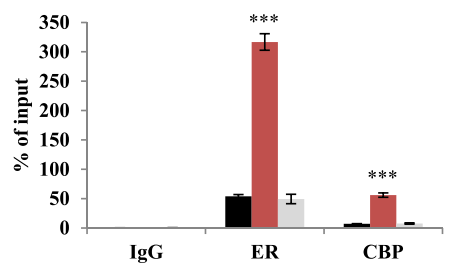

Fig. 4 25-HC and 27-HC enhance recruitment of ER to endogenous E-regulated genes in ER+ LTED cells. Wt-MCF7 and MCF7 LTED cells were treated with E2, 25-HC and 27-HC alone or in combination with ICI182780 (ICI) for 24 hours. mRNA was extracted and quantitative RT-PCR used to measure expression of TFF1. a Data shown are representative of three independent biological experiments. Bars: \pm SEM. b MCF7 LTED cells were synchronized using a-amanitin and treated with 25-HC for 45 minutes [26]. ChIP was carried out to assess the recruitment of ER to the GREB1 and TFF1 promoters, respectively. To provide evidence for an activated complex, histone deacetylase CBP recruitment was also assessed. c Effect of 27-HC on ER and CBP recruitment to the TFF1 and GREB1 promoters. Data shown are representative of three technical replicates. Bars: \pm SEM. DCC Dextran-coated charcoal, E2 estradiol, ER estrogen receptor alpha, ERE estrogen response elements, HC hydroxycholesterol, LTED, long-term estrogen deprivation, wt wild type

siEBP was not rescued by E2 addition (Additional file 8: Figure S2B).

\section{Discussion}

Despite the success of AIs in treating patients with ER+ $\mathrm{BC}$ and reducing their risk of dying from the disease, resistance remains a significant problem [50]. To study novel mechanisms of resistance to E-deprivation on an AI, we generated a panel of cell line models with varying genetic backgrounds and interrogated alterations in both their global gene transcriptome and proteome. Our main focus was to identify common adaptive mechanisms of resistance. Using pathway analysis, we showed a concordant upregulation of the cholesterol biosynthesis pathway in our LTED models that retained ER expression but not in those that lost expression of the steroid receptor.

Evidence suggests both primary and recurrent tumour cells have a high demand of lipids in order to proliferate and metastasize [44]. For instance, activation of the PI3K/ $\mathrm{AKT} / \mathrm{mTOR}$ pathway is strongly associated with lipogenesis $[44,51,52]$, as well as accumulation of cholesteryl esters in various cancers via SREBP1 and $L D L R$ activation [41]. In this setting, hyperactivation of PI3K/AKT/mTOR pathway activates SREBP1, thereby potentiating esterification and compartmentalization of cholesterol into lipid droplets, allowing uptake of fatty acids and leading to increased proliferation [42]. As $40 \%$ of BCs harbour activating mutation/amplification of PIK3CA or loss of PTEN, a feature modelled in our ER+ LTED cell lines, we 


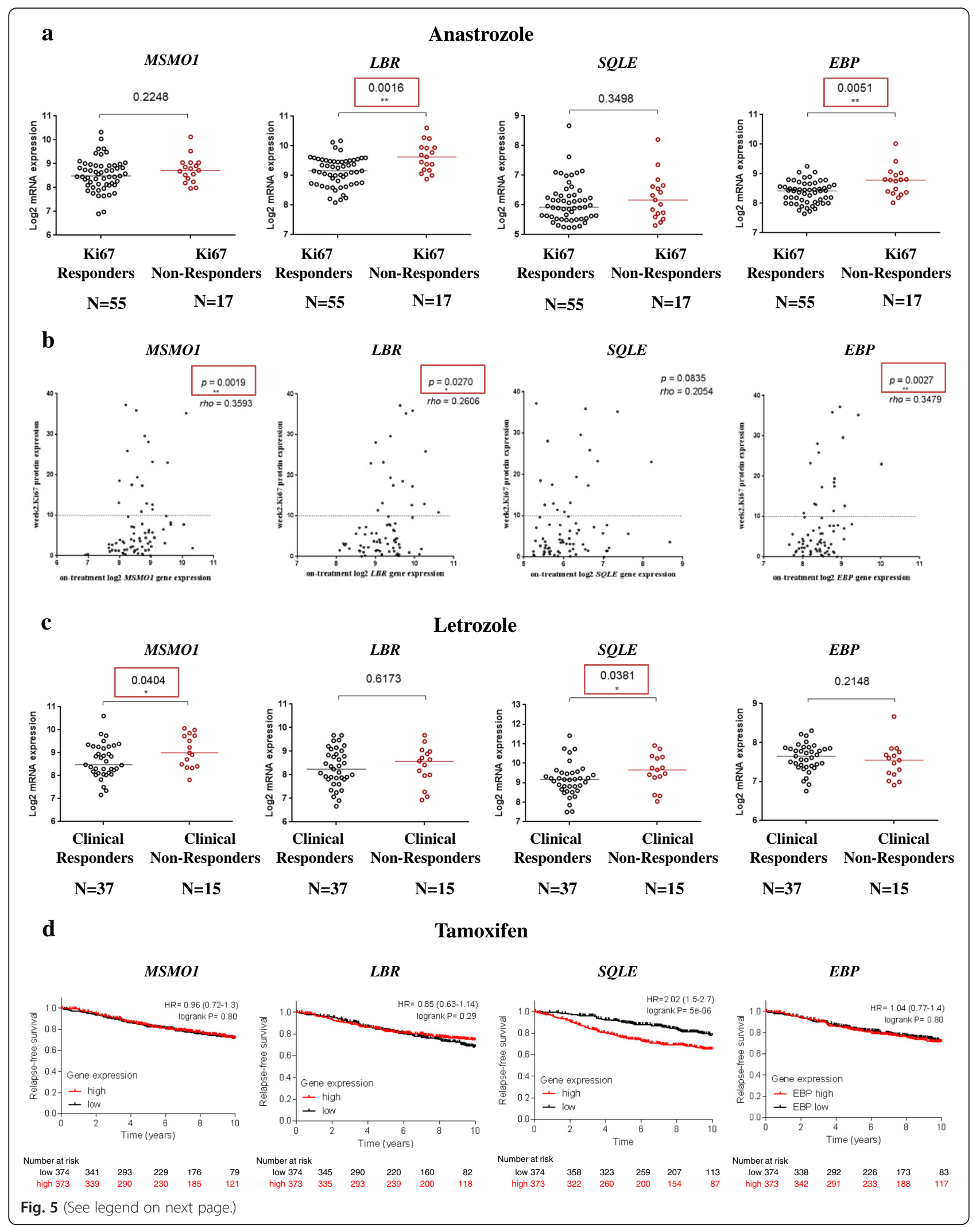


(See figure on previous page.)

Fig. 5 Enzymes within the cholesterol biosynthesis pathway are associated with poor response on tamoxifen. a On-treatment gene expression of $M S M O 1, \angle B R$, SQLE and EBP in patients treated with anastrozole. b Association of on-treatment gene expression of MSMO1, LBR, SQLE and EBP and 2-week Ki67 value. Spearman's rank correlation coefficients (rho) and $p$ values are depicted. c On-treatment gene expression of MSMO1, LBR, SQLE and EBP in patients treated with letrozole. Black, responders; red, non-responders. $\mathbf{d}$ Kaplan-Meier plots revealing the association of high or low pre-treatment gene expression of MSMO1, LBR, SQLE and EBP in ER+ BC patients treated with tamoxifen, from publicly available data collected over 10 years. Red, patients with higher gene expression; black, patients with lower gene expression

assessed mRNA levels of SREBP1, LDLR and HMGCR. However, expression at the transcript or protein was either undetected or downregulated. Additionally, ACAT1, which is important for cholesterol esterification and prevents cellular toxicity of excess cholesterol, was less abundant in the LTED at both the mRNA and protein level. Furthermore, the levels of esterified cholesterol were not significantly different between wt and LTED cells (data not shown), suggesting this axis is less important in the ER+ LTED phenotype.

There is compelling evidence for the role of cholesterol metabolites in promoting tumour growth $[45,47,53,54]$ and acting as endogenous SERMS [27, 46]. In particular, it has been hypothesized that $27-\mathrm{HC}$ may be the primary biochemical link between lipid metabolism and cancer [55]. We showed that both $25-\mathrm{HC}$ and $27-$ HC were elevated in our ER+ LTED models compared with their parental controls. Of note, addition of both oxysterols promoted ER-mediated transcription and enhanced recruitment of ER to EREs on both TFF1 and GREB1, two E-regulated genes. Furthermore, this process was antagonized by fulvestrant, suggesting a mechanism dependent on a functional ER-transcription axis. We hypothesized that both $25-\mathrm{HC}$ and $27-\mathrm{HC}$ may substitute for E2 in the LTED setting, a notion supported by our in-silico analysis, which showed that both oxysterols were capable of binding with the LBD located in the AF2 domain of ER.

Obesity and lipogenesis have been associated with increased $\mathrm{BC}$ risk and a worse outcome as a result of increased levels of adipocyte-secreted endocrine factors and insulin-like growth factors (IGFs) [56, 57]. Previously, we showed that gene signatures modelling both obesity and IGF signalling predicted a poor antiproliferative effect of anastrozole [13]. To assess whether these enzymes within the cholesterol biosynthesis pathway had relevance for clinical response or prognosis of $E R+B C$ treated with endocrine therapy that were upregulated in our ER+ LTED models, we interrogated in-silico data from patients treated with neoajuvant AI therapy or adjuvant tamoxifen. These analyses revealed that higher expression of four of the nine upregulated genes (MSMO1, EBP, LBR and SQLE) correlated with poor response to AI therapy judged either by clinical response [34] or by the validated response biomarker Ki67 [12, 35], but only SQLE associated with poor response to endocrine therapy or poor long-term outcome on such therapy or both. Previous studies have shown that SQLE is amplified in 10 $\%$ of $\mathrm{BC}$ [58] and that high expression is associated with poor prognosis in early-stage ER+ BC [59]. Studies have shown that the $8 \mathrm{p} 11-\mathrm{p} 12$ chromosomal region is a hotspot for genomic aberrations and that coamplification with the $M Y C$ oncogene (8q24.21) as well as altered transcriptional patterns (hypomethylation) of genes spanning 8q12.1-q24.22, which includes $S Q L E$, is associated with more aggressive tumours [60]. Taken together, this would suggest $S Q L E$ is indicative of poor prognosis while the other cholesterol biosynthesis genes associate more strongly and specifically with poor response to AI therapy. Of note, some genes involved in cholesterol biosynthesis are already incorporated in clinically relevant gene signatures. For instance, DHCR7, which was more abundant in our MCF7 LTED cells $(1.25$-fold, $p<0.001)$ but did not meet our stringent selection criteria, forms part of the eight-gene EndoPredict signature [61].

\section{Conclusion}

Taken together, these data highlight once again the importance of cholesterol biosynthesis in $\mathrm{BC}$ progression and the link with obesity as a marker of increased BC risk and poor outcome on AI therapy [62]. Our observations suggest that enzymes within the cholesterol biosynthesis pathway may be associated with acquired resistance to AI therapy. Clinical measurement, either by gene expression of pertinent enzymes within this complex network or by the assessment of $27-\mathrm{HC}$ and $25-$ $\mathrm{HC}$, may prove informative biomarkers. Our study highlights the need to evaluate the lowering of cholesterol on the impact of endocrine therapy.

\section{Additional files}

Additional file 1: Table S1. Changes in gene expression during long term estrogen deprivation (LTED). Univariate $p<0.001, \mathrm{FDR}<5 \%$, absolute $F C \geq 1.5$.

Additional file 2: Figure S1. Schematic representation of the cholesterol biosynthesis pathway (red text indicates enzymes shown to be upregulated in the ER+ LTED cell lines).

Additional file 3: Table S2. Alteration in transcript levels for genes within the cholesterol biosynthesis pathway. 
Additional file 4: Table S3. Validation of proteomic data showing expression of ER and known associated proteins. Protein abundance was measured using dimethyl labelling from wt-MCF7 (M) and MCF7 LTED (L). Changes are represented as fold change (wt-MCF7/MCF7 LTED). Negative values indicate inverted ratios for those $<1$.

Additional file 5: Table S4. Common upregulated pathways between the proteome and transcriptome in the MCF7 LTED versus wt-MCF7. Values shown as -log p-values.

Additional file 6: Table S5. Alteration of ACAT1 and $L D L R$ gene expression in LTED versus their corresponding wt.

Additional file 7: Table S6. Comparative abundance of ACAT1, which regulates cholesterol accumulation, presented as fold change (wt-MCF7/ MCF7 LTED).

Additional file 8: Figure S2. A. Kaplan-Meier plots revealing the influence of high or low expression of MSMO1, LBR, SQLE and EBP in relapse-free survival of 496 ER- BC patients treated with chemotherapy, from publicly available data collected over 10 years. B. wt-MCF7, MCF7 LTED and ZR75.1 LTED were treated with siRNA targeting siMSMO1, siLBR, siSQLE and siEBP. Wt-MCF7 were treated with or without E2. Change in proliferation was expressed as fold change relative to sicontrol. Bars represent \pm SEM from eight replicates. The assessment was carried out in two independent experiments.

\section{Abbreviations}

Al: aromatase inhibitor; BC: breast cancer; ChIP: chromatin immunoprecipitation; DCC: Dextran-coated charcoal; E: estrogen; E2: estradiol; ER: estrogen receptor alpha; ERE: estrogen response elements; HC: hydroxycholesterol; IGF: insulin-like growth factor; IPA: Ingenuity Pathway Analysis; LBD: ligand-binding domain; LC-MS/MS: liquid chromatography-tandem mass spectrometry; LTED: long-term estrogen deprivation; OGE: OFFGEL electrophoresis; RFS: relapse-free survival; SERM: selective estrogen receptor modulator; wt: wild type.

\section{Acknowledgements}

The authors thank The Breast Cancer Now Toby Robins Research Centre for generous funding. They also acknowledge NHS Trust funding to the Royal Marsden Hospital's NIHR Biomedical Research Centre. The authors thank Dr Faraz Khosravi Mardakheh for providing the OGE system. They also thank Professor Elsa Lundanes and Dr Steven Ray Haakon Wilson for providing the platform for the LC-MS/MS analysis of oxysterols.

\section{Authors' contributions}

L-AM and NS designed the study. NS, QG, SP, HR-L, MZ, RR, EF, AT and AB generated and analysed the data. L-AM, MD and NS wrote and edited the manuscript. All authors approved the final version of the manuscript.

\section{Competing interests}

The authors declare that they have no competing interests.

\section{Author details}

${ }^{1}$ The Breast Cancer Now Toby Robins Research Centre, The Institute of Cancer Research, London SW3 6JB, UK. ²Department of Chemistry, University of Oslo, 0371 Oslo, Norway. ${ }^{3}$ Academic Department of Biochemistry, Royal Marsden Hospital, London SW3 6JJ, UK. ${ }^{4}$ Proteomics Core Facility, Institute of Cancer Research, London SW3 6JB, UK.

Received: 3 March 2016 Accepted: 26 April 2016

Published online: 01 June 2016

\section{References}

1. Bonneterre J, Thuerlimann B, Robertson JFR, Krzakowski M, Mauriac L, Koralewski $P$, et al. Anastrozole versus tamoxifen as first-line therapy for advanced breast cancer in 668 postmenopausal women: results of the Tamoxifen or Arimidex Randomized Group Efficacy and Tolerability Study. J Clin Oncol. 2000;18:3748-57.

2. Nabholtz JM, Buzdar A, Pollak M, Harwin W, Burton G, Managalik A, et al. Anastrozole is superior to tamoxifen as first-line therapy for advanced breast cancer in postmenopausal women: results of a North American multicenter randomized trial. Arimidex Study Group. J Clin Oncol. 2000;18:3758-67.

3. Mouridsen BH, Gershanovich M, Sun Y, Boni C, Monnier A, Apffelstaedt J, et al. Superior efficacy of letrozole versus tamoxifen as first-line therapy for postmenopausal women with advanced breast cancer: results of a phase III study of the International Letrozole Breast Cancer Group. J Clin Oncol. 2001; 19:2596-606.

4. Forbes JF, Cuzick J, Buzdar A, Howell A, Tobias JS, Baum M. Effect of anastrozole and tamoxifen as adjuvant treatment for early-stage breast cancer: 100-month analysis of the ATAC trial. Lancet Oncol. 2008:9:45-53.

5. Musgrove EA, Sutherland RL. Biological determinants of endocrine resistance in breast cancer. Nat Rev Cancer. 2009;9:631-43.

6. Markopoulos CJ. Minimizing early relapse and maximizing treatment outcomes in hormone-sensitive postmenopausal breast cancer: efficacy review of Al trials. Cancer Metastasis Rev. 2010;29:581-94.

7. Arpino G, Green SJ, Allred DC, Lew D, Martino S, Osborne CK, et al. HER-2 amplification, HER-1 expression, and tamoxifen response in estrogen receptor-positive metastatic breast cancer: a Southwest Oncology Group Study. Clin Cancer Res. 2004;10:5670-6.

8. De Laurentiis M, Arpino G, Massarelli E, Ruggiero A, Carlomagno C, Ciardiello F, et al. A meta-analysis on the interaction between HER-2 expression and response to endocrine treatment in advanced breast cancer. Clin Cancer Res. 2005;11:4741-8.

9. Ellis MJ, Tao Y, Young O, White S, Proia AD, Murray J, et al. Estrogenindependent proliferation is present in estrogen-receptor HER2-positive primary breast cancer after neoadjuvant letrozole. J Clin Oncol. 2006;24:3019-25.

10. Martin LA, Farmer I, Johnston SRD, Ali S, Dowsett M. Elevated ERK1/ERK2/ estrogen receptor cross-talk enhances estrogen-mediated signaling during long-term estrogen deprivation. Endocr Relat Cancer. 2005;12 Suppl 1:S75-84.

11. Ma CX, Reinert T, Chmielewska I, Ellis MJ. Mechanisms of aromatase inhibitor resistance. Nat Rev Cancer. 2015;15:261-75.

12. Ellis MJ, Ding L, Shen D, Luo J, Suman VJ, Wallis JW, et al. Whole-genome analysis informs breast cancer response to aromatase inhibition. Nature. 2012:486:353-60.

13. Gao Q, Patani N, Dunbier AK, Ghazoui Z, Zvelebil M, Martin LA, et al. Effect of aromatase inhibition on functional gene modules in oestrogen receptor positive breast cancer and their relationship with antiproliferative response. Clin Cancer Res. 2014:20(9):2485-94.

14. Darbre PD, Curtis S, King RJB. Effects of estradiol and tamoxifen on human breast cancer cells in serum-free culture. Cancer Res. 1984;44:2790-3.

15. Du P, Kibbe WA, Lin SM. lumi: a pipeline for processing Illumina microarray. Bioinformatics. 2008:24:1547-8.

16. Zhao Y, Simon R. BRB-ArrayTools data archive for human cancer gene expression: a unique and efficient data sharing resource. Cancer Inform. 2008;6:9-15.

17. Boersema PJ, Raijmakers R, Lemeer S, Mohammed S, Heck AJR. Multiplex peptide stable isotope dimethyl labeling for quantitative proteomics. Nat Protoc. 2009;4:484-94

18. Di Palma S, Mohammed S, Heck AJR. ZIC-cHILIC as a fractionation method for sensitive and powerful shotgun proteomics. Nat Protoc 2012:7:2041-55.

19. Cox J, Mann M. MaxQuant enables high peptide identification rates, individualized p.p.b.-range mass accuracies and proteome-wide protein quantification. Nat Biotechnol. 2008;26:1367-72.

20. Cox J, Neuhauser N, Michalski A, Scheltema RA, Olsen JV, Mann M. Andromeda: a peptide search engine integrated into the MaxQuant environment. J Proteome Res. 2011:10:1794-805.

21. Cox J, Matic I, Hilger M, Nagaraj N, Selbach M, Olsen JV, et al. A practical guide to the MaxQuant computational platform for SILAC-based quantitative proteomics. Nat Protoc. 2009;4:698-705.

22. Ribas R, Ghazoui Z, Gao Q, Pancholi S, Rani A, Dunbier A, et al. Identification of chemokine receptors as potential modulators of endocrine resistance in estrogen receptor positive breast cancers. Breast Cancer Res. 2014;16:447.

23. Martin LA, Farmer I, Johnston SRD, Ali S, Marshall C, Dowsett M. Enhanced estrogen receptor (ER) alpha, ERBB2, and MAPK signal transduction pathways operate during the adaptation of MCF-7 cells to long term estrogen deprivation. J Biol Chem. 2003:278:30458-68.

24. Weigel MT, Ghazoui Z, Dunbier A, Pancholi S, Dowsett M, Martin LA. Preclinical and clinical studies of estrogen deprivation support the PDGF/ Abl pathway as a novel therapeutic target for overcoming endocrine resistance in breast cancer. Breast Cancer Res. 2012:14:R78.

25. Schmidt D, Wilson MD, Spyrou C, Brown GD, Hadfield J, Odom DT. ChIP-seq: using high-throughput sequencing to discover protein-DNA interactions. Methods. 2009;48:240-8. 
26. Metivier R, Huebner MR, Reid G, Brand H, Kos M, Gannon F. Estrogen receptor-a directs ordered, cyclical, and combinatorial recruitment of cofactors on a natural target promoter. Cell. 2003;115:751-63.

27. DuSell CD, McDonnell DP. 27-Hydroxycholesterol: a potential endogenous regulator of estrogen receptor signaling. Trends Pharmacol Sci. 2008; 29(August):510-4.

28. Lee JS, Ettinger B, Stanczyk FZ, Vittinghoff E, Hanes V, Cauley JA, et al. Comparison of methods to measure low serum estradiol levels in postmenopausal women. J Clin Endocrinol Metab. 2006;91(July):3791-7.

29. Roberg-Larsen H, Lund K, Vehus T, Solberg N, Vesterdal C, Misaghian D, et al. Highly automated nano-LC/MS-based approach for thousand cellscale quantification of side chain-hydroxylated oxysterols. J Lipid Res. 2014:55:1531-6.

30. Grosdidier A, Zoete V, Michielin O. SwissDock, a protein-small molecule docking web service based on EADock DSS. Nucleic Acids Res. 2011:39:W270-7.

31. Grosdidier A, Zoete V, Michielin O. Fast docking using the CHARMM force field with EADock DSS. J Comput Chem. 2011:32:2149-59.

32. Smith IE, Walsh G, Skene A, Llombart A, Mayordomo II, Detre S, et al. A phase II placebo-controlled trial of neoadjuvant anastrozole alone or with gefitinib in early breast cancer. J Clin Oncol. 2007;25:3816-22.

33. Dunbier AK, Ghazoui Z, Anderson H, Salter J, Nerurkar A, Osin P, et al. Molecular profiling of aromatase inhibitor-treated postmenopausal breast tumors identifies immune-related correlates of resistance. Clin Cancer Res. 2013;19:2775-86.

34. Miller WR, Larionov A, Renshaw L, Anderson TJ, Walker JR, Krause A, et al. Gene expression profiles differentiating between breast cancers clinically responsive or resistant to letrozole. J Clin Oncol. 2009;27:1382-7.

35. Dowsett M, Nielsen TO, A'Hern R, Bartlett J, Coombes RC, Cuzick J, et al. Assessment of Ki67 in breast cancer: recommendations from the international Ki67 in breast cancer working Group. J Natl Cancer Inst. 2011;103:1656-64.

36. Györffy B, Lanczky A, Eklund AC, Denkert C, Budczies J, Li Q, et al. An online survival analysis tool to rapidly assess the effect of 22,277 genes on breast cancer prognosis using microarray data of 1,809 patients. Breast Cancer Res Treat. 2010;123:725-31.

37. Sharpe $L$, Brown AJ. Controlling cholesterol synthesis beyond 3-hydroxy-3methylglutaryl-CoA reductase (HMGCR). J Biol Chem. 2013;288:18707-15.

38. Wilcox CB, Feddes GO, Willett-Brozick JE, Hsu L-C, DeLoia JA, Baysal BE. Coordinate up-regulation of TMEM97 and cholesterol biosynthesis genes in normal ovarian surface epithelial cells treated with progesterone: implications for pathogenesis of ovarian cancer. BMC Cancer. 2007;7:223.

39. Cyster JG, Dang EV, Reboldi A, Yi T. 25-Hydroxycholesterols in innate and adaptive immunity. Nat Rev Immunol. 2014;14(November):731-43.

40. Spann NJ, Glass CK. Sterols and oxysterols in immune cell function. Nat Immunol. 2013;14:893-900.

41. Yue S, Li J, Lee SY, Lee HJ, Shao T, Song B, et al. Cholesteryl ester accumulation induced by PTEN loss and PI3K AKT activation underlies human prostate cancer aggressiveness. Cell Metab. 2014;19:393-406.

42. Peck B, Schulze A. Cholesteryl esters: fueling the fury of prostate cancer. Cell Metab. 2014;19:350-2

43. Miller TW, Balko JM, Arteaga CL. Phosphatidylinositol 3-kinase and antiestrogen resistance in breast cancer. J Clin Oncol. 2011;29:4452-61.

44. Guo D, Reinitz F, Youssef M, Hong C, Nathanson D, Akhavan D, et al. An LXR agonist promotes glioblastoma cell death through inhibition of an EGFR/ AKT/SREBP-1/LDLR-dependent pathway. Cancer Discov. 2011;1:442-56.

45. DuSell CD, Umetani M, Shaul PW, Mangelsdorf DJ, McDonnell DP. 27hydroxycholesterol is an endogenous selective estrogen receptor modulator. Mol Endocrinol. 2008;22(January):65-77.

46. Umetani M, Domoto H, Gormley AK, Yuhanna IS, Cummins CL, Javitt NB, et al. 27-Hydroxycholesterol is an endogenous SERM that inhibits the cardiovascular effects of estrogen. Nat Med. 2007;13:1185-92.

47. Nguyen VTM, Barozzi I, Faronato M, Lombardo Y, Steel JH, Patel N, et al. Differential epigenetic reprogramming in response to specific endocrine therapies promotes cholesterol biosynthesis and cellular invasion. Nat Commun. 2015:6:10044.

48. Lappano R, Recchia AG, De Francesco EM, Angelone T, Cerra MC, Picard D, et al. The cholesterol metabolite 25-hydroxycholesterol activates estrogen receptor $\mathrm{a}$-mediated signaling in cancer cells and in cardiomyocytes. PLoS One. 2011;6:e16631.

49. Brzozowski AM, Pike AC, Dauter Z, Hubbard RE, Bonn T, Engström O, et al. Molecular basis of agonism and antagonism in the oestrogen receptor. Nature. 1997;389:753-8.
50. (EBCTCG) EBCTCG. Aromatase inhibitors versus tamoxifen in early breast cancer: patient-level meta-analysis of the randomised trials. Lancet. 2015; 386:1341-52.

51. Guo D, Prins RM, Dang J, Kuga D, Iwanami A, Soto H, et al. EGFR signaling through an Akt-SREBP-1-dependent, rapamycin-resistant pathway sensitizes glioblastomas to antilipogenic therapy. Sci Signal. 2009;2:ra82.

52. Bauer DE, Hatzivassiliou G, Zhao F, Andreadis C, Thompson CB. ATP citrate lyase is an important component of cell growth and transformation. Oncogene. 2005;24:6314-22.

53. Wu Q, Ishikawa T, Sirianni R, Tang H, McDonald JG, Yuhanna IS, et al. 27Hydroxycholesterol promotes cell-autonomous, ER-positive breast cancer growth. Cell Rep. 2013;5:637-45.

54. Nelson ER, Wardell SE, Jasper JS, Park S, Suchindran S, Howe MK, et al. 27Hydroxycholesterol links hypercholesterolemia and breast cancer pathophysiology. Science. 2013:342:1094-8.

55. McDonnell DP, Park S, Goulet MT, Jasper J, Wardell SE, Chang C-Y, et al. Obesity, cholesterol metabolism and breast cancer pathogenesis. Cancer Res. 2014;74:4976-82.

56. Creighton CJ, Casa A, Lazard Z, Huang S, Tsimelzon A, Hilsenbeck SG, et al. Insulin-like growth factor-I activates gene transcription programs strongly associated with poor breast cancer prognosis. J Clin Oncol. 2008;26:4078-85.

57. Creighton CJ, Sada YH, Zhang Y, Tsimelzon A, Wong H, Dave B, et al. A gene transcription signature of obesity in breast cancer. Breast Cancer Res Treat. 2012;132:993-1000.

58. Koboldt DC, Fulton RS, McLellan MD, Schmidt H, Kalicki-Veizer J, McMichael JF, et al. Comprehensive molecular portraits of human breast tumours. Nature. 2012;490:61-70.

59. Helms MW, Kemming D, Pospisil H, Vogt $U$, Buerger $H$, Korsching $E$, et al. Squalene epoxidase, located on chromosome $8 q 24.1$, is upregulated in $8 q+$ breast cancer and indicates poor clinical outcome in stage I and II disease. Br J Cancer. 2008;99:774-80.

60. Parris TZ, Kovács A, Hajizadeh S, Nemes S, Semaan M, Levin M, et al. Frequent MYC coamplification and DNA hypomethylation of multiple genes on $8 \mathrm{q}$ in 8p11-p12-amplified breast carcinomas. Oncogenesis. 2014;3(January),e95.

61. Filipits $M$, Rudas $M$, Jakesz R, Dubsky P, Fitzal F, Singer CF, et al. A new molecular predictor of distant recurrence in ER-positive, HER2-negative breast cancer adds independent information to conventional clinical risk factors. Clin Cancer Res. 2011;17:6012-20.

62. Sestak I, Harvie M, Howell A, Forbes JF, Dowsett M, Cuzick J. Weight change associated with anastrozole and tamoxifen treatment in postmenopausal women with or at high risk of developing breast cancer. Breast Cancer Res Treat. 2012:134:727-34.

\section{Submit your next manuscript to BioMed Central and we will help you at every step:}

- We accept pre-submission inquiries

- Our selector tool helps you to find the most relevant journal

- We provide round the clock customer support

- Convenient online submission

- Thorough peer review

- Inclusion in PubMed and all major indexing services

- Maximum visibility for your research

Submit your manuscript at www.biomedcentral.com/submit
) Biomed Central 